\title{
Postpartum Reclassification of Glycemic Status in Women with Gestational Diabetes Mellitus and Associated Risk Factors
}

\section{Reclassificação pós-parto do estado glicêmico em mulheres com diabetes mellitus gestacional e fatores de risco associados}

\author{
Jacy Maria Alves ${ }^{1}$ Aline Stollmeier ${ }^{2}$ Isabelle Gasparetto Leite ${ }^{2}$ Camilla Gallo Pilger ${ }^{2}$ \\ Josiane Cristine Melchioretto Detsch ${ }^{1}$ Rosana Bento Radominski ${ }^{1}$ Rosângela Roginski Réa ${ }^{1}$ \\ ${ }^{1}$ Endocrinology and Metabolism Service, Hospital de Clínicas, \\ Universidade Federal do Paraná (UFPR), Curitiba, PR, Brazil \\ Address for correspondence Jacy Maria Alves, MD, MSc, Hospital de \\ Clínicas, Universidade Federal do Paraná, Avenida Agostinho Leão Junior, \\ 2 Medical School, Universidade Federal do Paraná, Curitiba, PR, Brazil \\ 285, 80030-110, Curitiba, PR, Brasil (e-mail: jacy.alves@yahoo.com.br).
}

Rev Bras Ginecol Obstet 2016;38:381-390.

\begin{abstract}
Keywords

- gestational diabetes

- postpartum test

- type 2 diabetes

- oral glucose tolerance test

- risk factors

Objective The aims of the study were to evaluate, after pregnancy, the glycemic status of women with history of gestational diabetes mellitus (GDM) and to identify clinical variables associated with the development of type 2 diabetes mellitus (T2DM), impaired fasting glucose (IFG), and impaired glucose tolerance (IGT).

Methods Retrospective cohort of 279 women with GDM who were reevaluated with an oral glucose tolerance test (OGTT) after pregnancy. Characteristics of the index pregnancy were analyzed as risk factors for the future development of prediabetes (IFG or IGT), and T2DM. Results: T2DM was diagnosed in 34 (12.2\%) patients, IFG in 58 (20.8\%), and IGT in 35 (12.5\%). Women with postpartum T2DM showed more frequently a family history of T2DM, higher pre-pregnancy body mass index (BMI), lower gestational age, higher fasting and 2-hour plasma glucose levels on the OGTT at the diagnosis of GDM, higher levels of hemoglobin A1c, and a more frequent insulin requirement during pregnancy. Paternal history of T2DM (odds ratio $[O R]=5.67 ; 95 \%$ confidence interval $[95 \% \mathrm{Cl}]=1.64-19.59 ; p=0.006)$, first trimester fasting glucose value $(\mathrm{OR}=1.07 ; 95 \% \mathrm{Cl}=1.03-1.11 ; p=0.001)$, and insulin treatment during pregnancy $(O R=15.92 ; 95 \% \mathrm{Cl}=5.54-45.71 ; p<0.001)$ were significant independent risk factors for the development of T2DM.

Conclusion A high rate of abnormal glucose tolerance was found in women with previous GDM. Family history of T2DM, higher pre-pregnancy BMI, early onset of GDM, higher glucose levels, and insulin requirement during pregnancy were important risk factors for the early identification of women at high risk of developing T2DM. These findings may be useful for developing preventive strategies.
\end{abstract}

received

February 4, 2016

accepted

July 19, 2016

published online

August 19, 2016
DOI http://dx.doi.org/

10.1055/s-0036-1588008. ISSN 0100-7203.
Copyright $(\underset{0}{ } 2016$ by Thieme Publicações License terms

Ltda, Rio de Janeiro, Brazil
()(1) $\odot \circledast$ 


\section{Resumo}

\section{Descritores}

- diabetes gestacional

- reavaliação pós-parto

- diabetes tipo 2

- teste oral de tolerância à glicose

- fatores de risco
Objetivo Os objetivos do estudo foram avaliar o estado glicêmico de mulheres com história de diabetes mellitus gestacional (DMG) após o parto e identificar fatores associados ao desenvolvimento de diabetes mellitus tipo 2 (DM2), glicemia de jejum alterada (GJA) e tolerância diminuída à glicose (TDG).

Métodos Coorte retrospectiva de 279 mulheres com DMG reavaliadas com um teste oral de tolerância à glicose (TOTG) após a gestação. Foram analisados fatores prognósticos da gestação índice e fatores de risco para o futuro desenvolvimento de pré-diabetes (GJA ou TDG) e DM2. Resultados: Diagnosticou-se DM2 em 34 pacientes (12,2\%), GJA em 58 (20,8\%) e TDG em 35 (12,5\%). Mulheres que evoluíram para DM2 apresentaram maior frequência de história familiar de DM2, índice de massa corporal (IMC) pré-gestacional mais elevado, menor idade gestacional, níveis superiores de glicemia de jejum e 2 horas após glicose no TOTG ao diagnóstico do DMG, hemoglobina glicada mais elevada, e uso mais frequente de insulina na gestação. História paterna de DM2 (odds ratio $[\mathrm{OR}]=5,67$; intervalo de confiança de 95\% [IC95\%] $=1,64-19,59 ; p=0,006)$, glicemia de jejum do primeiro trimestre (OR $=1,07 ; \mathrm{IC} 95 \%=1,03-1,11 ; p=0,001)$ e o uso de insulina na gestação $(\mathrm{OR}=15,92$; $\mathrm{IC95 \%}=5,54-45,71 ; p<0,001)$ foram fatores de risco independentes para o desenvolvimento de DM2.

Conclusão Houve elevada incidência de alterações no metabolismo da glicose em mulheres com DMG prévio. História familiar de DM2, IMC pré-gestacional elevado, DMG diagnosticado mais precocemente na gestação, com glicemias mais elevadas e necessidade de insulina, foram importantes fatores de risco associados à identificação precoce de mulheres com alto risco de desenvolvimento de DM2. Este conhecimento pode ser útil para o desenvolvimento de estratégias de prevenção.

\section{Introduction}

Gestational diabetes mellitus (GDM) is historically defined as "any degree of glucose intolerance with onset or first recognition during pregnancy", and may or may not persist after labor. ${ }^{1}$ This concept had limitations, considering the inclusion of pregnant women with type 2 diabetes mellitus (T2DM) not previously diagnosed. Thus, it was modified after the study Hyperglycemia and Adverse Pregnancy Outcome (HAPO), which evaluated more than 25,000 pregnant women and intended to find the cutoff point of the maternal plasma glucose associated to the increase of adverse perinatal events. ${ }^{2}$ The diagnostic patterns for GDM were revised, and the recommendation according to the International Association of Diabetes and Pregnancy Study Groups (IADPSG) since 2010 is that pregnant women who fit the diagnosis of T2DM at the first prenatal appointment be diagnosed as having overt diabetes. New threshold values (cutoff points) to diagnose GDM were adopted, defined as the following values on the oral glucose tolerance test (OGTT) with $75 \mathrm{~g}$ of glucose: fasting plasma glucose $\geq 92 \mathrm{mg} / \mathrm{dL}$, after 1 hour $\geq 180 \mathrm{mg} / \mathrm{dL}$ and/or after 2 hours $\geq 153 \mathrm{mg} / \mathrm{dL}$; a single abnormal value is enough to diagnose GDM. ${ }^{3,4}$

The traditionally defined prevalence of GDM was of 7\% of pregnancies (varying from 1 to $14 \%$, depending on the studied population and the diagnostic criteria that were used), and was associated with adverse outcomes, both maternal and fetal. ${ }^{4}$ After the alterations in the diagnostic criteria, the global prevalence of gestational hyperglycemia increased and was estimated at $\sim 17 \%$, with some regional variations. $^{5,6}$ The study of Trujillo et al $^{7}$ applied such parameters to a cohort of more than 5,000 pregnant women of the Brazilian Gestational Diabetes Study, conducted between 1991 and 1995, finding an estimated prevalence of $18 \%$ of GDM.

Women who had pregnancies complicated by GDM are at an increased risk of developing T2DM in the postpartum period when compared with those with normal plasma glucose levels during pregnancy. ${ }^{8}$ A meta-analysis evaluated 28 studies including women with previous GDM, with follow-up ranging between 6 weeks and 28 years after the end of pregnancy, and showed rates of T2DM between 2.6 and $70 \%$, depending on ethnicity, diagnostic criteria, and the follow-up period. ${ }^{9}$

Women with history of GDM are recommended for reevaluation regarding the persistence or not of abnormal glucose tolerance within 6 to 12 weeks after labor, following the same diagnostic criteria of the OGTT used outside pregnancy, or with the fasting plasma glucose, but the OGTT is the most sensitive test. If the tests show a normal result, the reevaluation could be done every 3 years. Patients presenting impaired fasting glucose (IFG) and/or impaired glucose tolerance (IGT) must be reevaluated annually. ${ }^{10}$ 
Some studies have already shown that the establishment of T2DM may be postponed or avoided in high-risk groups through changes in lifestyle or medication use. ${ }^{11,12}$ Therefore, the identification of possible characteristics associated with the development of T2DM in women with previous GDM could contribute to the stratification of risk, aiming at prevention programs.

The objective of the study was to reevaluate the glycemic status in women with history of GDM and to identify associations among the pre-pregnancy and pregnancy characteristics and the progression to different glycemic outcomes: T2DM, IFG, and IGT.

\section{Methods}

A retrospective cohort of outpatients was followed up at the Prenatal Diabetes Clinic of the Endocrinology Service of Hospital de Clínicas, Universidade Federal do Paraná (HCUFPR), a tertiary care reference hospital for high-risk pregnancies. Those women presented altered plasma glucose levels during pregnancy, with or without risk factors identified for GDM, and no previous diagnosis of diabetes mellitus (DM). Women who returned to the clinic for postnatal evaluation from 6 to 12 weeks after labor, as advised during prenatal care, were included in the study. Exclusion criteria were the following: diagnosis of type 1 diabetes mellitus (T1DM) or T2DM, according to the criteria of prompt increase of fasting glucose in the first weeks of pregnancy; and/or not having the postpartum OGTT. The study was approved by the HC-UFPR Human Research Ethics Committee.

All records (including standard forms filled by the Endocrinology and Obstetrics team) of patients with GDM followed by the Prenatal Diabetes Clinic of the HC-UFPR Endocrinology and Obstetrics Service between November 2001 and March 2013 were analyzed. The patients who had performed at least one OGTT during the postpartum follow-up care (or who had a fasting plasma glucose compatible with the diagnosis of T2DM) were included in the study. Patients with more than one OGTT during follow-up had the last test performed used for analysis.

Data were collected from the forms filled out at every appointment, the patient's records, and the Hospital Information System, and through active search by telephone contact with patients who did not return after labor for the OGTT.

The diagnosis of GDM followed the recommendations of the $2^{\text {nd }}$ Meeting of the Diabetes and Pregnancy Task Force ${ }^{13}$ until 2011: after positive screening (fasting plasma glucose $\geq 85 \mathrm{mg}$ / $\mathrm{dL}), 75$-g OGTT was performed, and GDM was diagnosed if fasting plasma glucose was $\geq 110 \mathrm{mg} / \mathrm{dL}$ and/or 2-hour plasma glucose after 75 -g glucose overload was $\geq 140 \mathrm{mg} / \mathrm{dL}$. After the release of the International Association of Diabetes and Pregnancy Study Groups (IADPSG) ${ }^{3}$ guidelines and their inclusion in the recommendations by the American Diabetes Association (ADA), ${ }^{10} \mathrm{GDM}$ was diagnosed when fasting plasma glucose was $\geq 92 \mathrm{mg} / \mathrm{dL}$ at any gestational age, or by using the 75-g OGTT, GDM being diagnosed when at least one of the following was found: fasting plasma glucose $\geq 92 \mathrm{mg} / \mathrm{dL} ; 1$ hour plasma glucose $\geq 180 \mathrm{mg} /$ $\mathrm{dL}$; and/or 2-hour plasma glucose $\geq 153 \mathrm{mg} / \mathrm{dL}$.
During the prenatal care appointments, a standard form was filled out with questions about the current and previous medical history of each patient with GDM: age of the patient at diagnosis of GDM; informed pre-pregnancy weight, prepregnancy and at GDM diagnosis height and body mass index (BMI), calculated by the equation: weight $(\mathrm{kg}) /$ height $\left(\mathrm{m}^{2}\right)$; family history of T2DM; history of GDM in previous pregnancies; hypertension history or history of hypertensive disorders of pregnancy; gestational age at the beginning of GDM care; fasting plasma glucose values at the first trimester of pregnancy; OGTT glucose values and mean hemoglobin A1c (A1c) in the index pregnancy; the need for insulin treatment (or metformin) during pregnancy; and weight gain until the end of pregnancy (considered excessive or not). Throughout the follow-up period, physical tests were performed for weight, blood pressure and obstetric parameters evaluation. The recommendations of the Institute of Medicine ${ }^{14}$ were used to classify the weight gain during pregnancy as insufficient, adequate or excessive, according to the pre-pregnancy body mass index (BMI). Pregnant women with BMI $\leq 18.5 \mathrm{~kg} / \mathrm{m}^{2}$ should gain between 12.5 and $18 \mathrm{~kg}$; the ones with BMI from 18.5 to $24.9 \mathrm{~kg} / \mathrm{m}^{2}$, between 11.5 and $16 \mathrm{~kg}$; overweight women (BMI from 25 to $29.9 \mathrm{~kg} / \mathrm{m}^{2}$ ), between 7 and $11.5 \mathrm{~kg}$; and obese women (BMI $\left.\geq 30 \mathrm{~kg} / \mathrm{m}^{2}\right)$, between 5 to $9 \mathrm{~kg} .{ }^{14}$

Patients were advised to follow a dietary treatment. Glucose control was considered good if fasting plasma glucose was $<95 \mathrm{mg} / \mathrm{dL}, 1$ hour postprandial $<140 \mathrm{mg} /$ $\mathrm{dL}$, and 2-hour postprandial $<120 \mathrm{mg} / \mathrm{dL}$. When one or more values of plasma glucose were beyond these therapeutic targets after 2 weeks of lifestyle modification, or when the ultrasonographic evaluation showed signs of excessive fetal growth, pharmacological treatment was indicated.

\section{Analyzed Results}

First, we made a comparison between the group of patients who returned for postpartum reevaluation of glucose tolerance status and the group who did not return and who was, therefore, excluded from the next analysis of subgroups, to ensure we had similar samples. Thus, we were able to verify if the patients who returned for the reevaluation had any special risk factor that could lead to a bias in the analysis, overestimating or underestimating the results, thus limiting or jeopardizing our conclusions.

Patients who returned after labor for reevaluation of glucose tolerance status were divided into four subgroups: T2DM, IFG, IGT, and normal glucose tolerance (NGT). Type 2 diabetes mellitus was diagnosed when fasting plasma glucose was $\geq 126 \mathrm{mg} / \mathrm{dL}$ and/or 2-hour after 75-g plasma glucose $\geq 200 \mathrm{mg} / \mathrm{dL}$; IFG, when fasting plasma glucose was $\geq 100 \mathrm{mg} / \mathrm{dL}$ and $<126 \mathrm{mg} / \mathrm{dL}$ and 2-hour after 75 -g normal glucose $(<140 \mathrm{mg} / \mathrm{dL})$; and IGT, when glucose values 2-hour after 75-g glucose were $\geq 140 \mathrm{mg} / \mathrm{dL}$ and $<200 \mathrm{mg} /$ $\mathrm{dL}$ and fasting plasma glucose was $<126 \mathrm{mg} / \mathrm{dL}$.

\section{Laboratory Tests}

Plasma glucose was measured by the hexokinase method, and the hemoglobin A1c by high performance liquid chromatography (HPLC). 


\section{Statistical Analysis}

Pre-gestational and gestational characteristics associated with each clinical outcome were expressed as mean and standard deviation for quantitative variables, and as absolute and relative frequency (percentage) in case of categorical variables. For the numeric variable "time elapsed from the first appointment at the GDM care clinic until the performance of OGTT postpartum", besides the mean and standard deviation, there were also nominated minimum, maximum, and median values in the corresponding table.

To compare the groups of patients included (who returned for postpartum reevaluation of glucose tolerance status) and the ones excluded from the study (patients who did not return), the Student $t$-test was used for the quantitative variables, and the Fisher's exact test or the Chi-square test for categorical variables.

For patients who performed at least one OGTT in the postpartum period and were divided into the subgroups T2DM, IFG, IGT and NGT, the statistical analysis was performed as follows: in the univariate analysis, the groups were compared with analysis of variance (ANOVA) in case of numeric variables with normal distribution, or with the Kruskal-Wallis test for non-parametric variables. For categorical variables, the Chi-square test was used for comparison. In a multivariate analysis with binary logistic regression, independent risk factors for the development of T2DM, IFG and IGT, comparing with NGT patients, were searched, and with the backward process, a final model was created with only the most important variables to determine the risk of the studied disease. Values of $p<0.05$ showed statistical relevance. The analyses were performed with the statistical software Minitab, version 16.1 (Champaign, IL, USA).

\section{Results}

From a total of 1,518 pregnancies diagnosed with GDM followed up in our service from November 2001 to March 2013, 279 patients presented some postpartum OGTT (18.4\%). From these 279 women who were included in the subgroup analysis, 51 (18.3\%) were diagnosed with the new GDM criteria of the IADPSG/ADA. ${ }^{3,4}$

- Table 1 shows the baseline characteristics of the patients who returned $(n=279)$ and the ones who did not return for the postpartum reevaluation $(n=1,239)$. The only statistically different characteristic between these groups was the gestational age at the diagnosis of GDM, which was lower in patients included in our study (30.7 weeks versus 31.7 weeks; $p=0.002$ ).

Among the 279 patients reevaluated in the postpartum period, 127 (45.5\%) showed some rate of abnormal glucose tolerance: 34 (12.2\%) were diagnosed with T2DM; 93 (33.3\%) were considered pre-diabetic (IFG and/or IGT): 58 (20.8\%) showed isolated IFG, and 35 (12.5\%) showed IGT; and 152 women (54.5\%) sustained NGT (-Fig. 1).

Concerning family history, women whose mothers presented T2DM had higher chances of developing T2DM in the

Table 1 Baseline characteristics of patients who returned at postpartum for reevaluation of the glycemic status and the patients who did not return

\begin{tabular}{|l|l|l|l|}
\hline Baseline characteristics & $\begin{array}{l}\text { Postpartum reevaluation } \\
(\boldsymbol{n}=\mathbf{2 7 9 )}\end{array}$ & $\begin{array}{l}\text { No postpartum reevaluation } \\
(\boldsymbol{n}=\mathbf{1 , 2 3 9 )}\end{array}$ & $\boldsymbol{p}$ \\
\hline Age at GDM diagnosis (years) & $32.1 \pm 6.1$ & $31.8 \pm 6.4$ & $0.530^{*}$ \\
\hline Father with T2DM & $40(14.3)$ & $175(14.1)$ & $0.927^{* *}$ \\
\hline Mother with T2DM & $85(30.5)$ & $333(26.9)$ & $0.225^{* *}$ \\
\hline Pre-gestational weight $(\mathrm{kg})$ & $70.6 \pm 14.7$ & $71.7 \pm 16.6$ & $0.288^{*}$ \\
\hline BMI 1 (kg/m $\left.{ }^{2}\right)$ & $27.9 \pm 5.7$ & $28.2 \pm 6.1$ & $0.596^{*}$ \\
\hline $\begin{array}{l}\text { History of chronic hypertension or hypertensive } \\
\text { pregnancy disorders }\end{array}$ & $75(26.9)$ & $315(25.4)$ & $0.615^{* *}$ \\
\hline $\begin{array}{l}\text { Gestational age at diagnosis of index pregnancy } \\
\text { with GDM (weeks) }\end{array}$ & $30.7 \pm 4.7$ & $31.7 \pm 4.7$ & $0.002^{*}$ \\
\hline First trimester fasting plasma glucose $(\mathrm{mg} / \mathrm{dL})$ & $89.1 \pm 12.5$ & $88.1 \pm 12.1$ & $0.240^{*}$ \\
\hline Fasting plasma glucose - OGTT (mg/dL) & $95.7 \pm 19.3$ & $95.3 \pm 18.2$ & $0.744^{*}$ \\
\hline 75-g-2-hour glucose - OGTT (mg/dL) & $167.8 \pm 31.3$ & $168.0 \pm 31.1$ & $0.906^{*}$ \\
\hline Gestational weight at diagnosis of GDM (kg) & $79.3 \pm 14.8$ & $80.1 \pm 16.3$ & $0.475^{*}$ \\
\hline BMl 2 (kg/m $\left.{ }^{2}\right)$ & $31.4 \pm 5.9$ & $31.4 \pm 5.9$ & $0.933^{*}$ \\
\hline Insulin/metformin treatment in pregnancy & $84 / 2$ & $345 / 8$ & $(27.8 / 0.6)$ \\
\hline
\end{tabular}

Abbreviations: BMI 1, body mass index, with the pre-gestational weight; BMI 2, body mass index, with the gestational weight at GDM diagnosis; GDM, gestational diabetes mellitus; OGTT, oral glucose tolerance test; T2DM, type 2 diabetes mellitus.

Notes: Results are expressed as: mean \pm standard deviation or $\mathrm{n}(\%)$.

*Student's $t$-test, $p<0.05$; values are expressed as mean \pm standard deviation.

${ }^{* *}$ Fisher's exact test, $p<0.05$; values are expressed as $\mathrm{n}(\%)$. $\dagger$ Chi-square test, $p<0.05$; values are expressed as $\mathrm{n}(\%)$. 


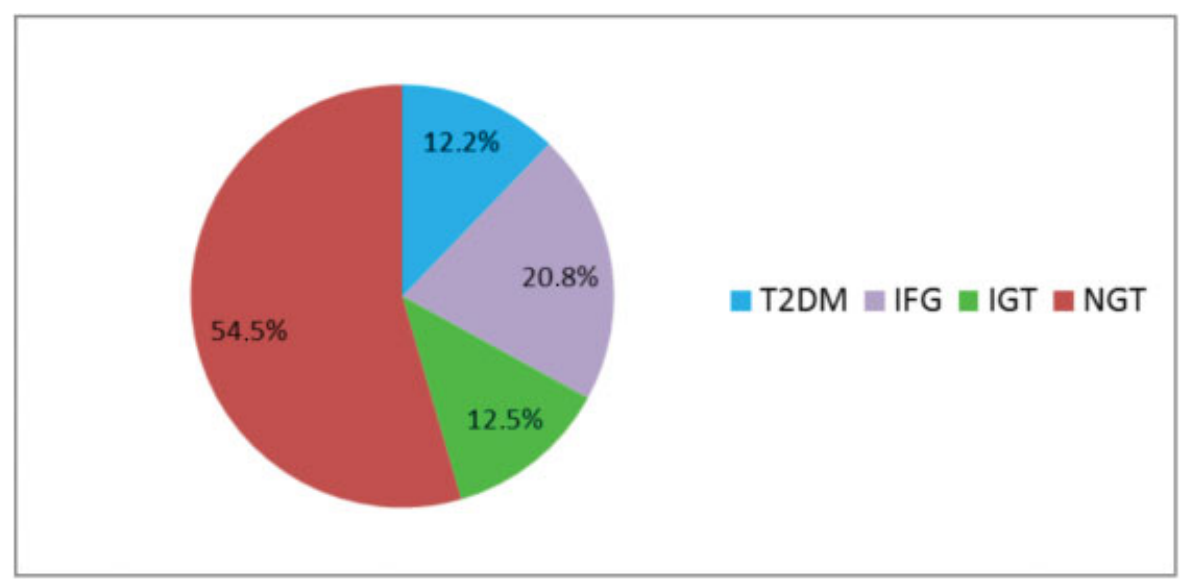

Fig. 1 Postpartum glycemic status in 279 women with history of GDM. T2DM, type 2 diabetes mellitus; IFG, impaired fasting glucose; IGT, impaired glucose tolerance; NGT, normal glucose tolerance.

postpartum period $(p=0.009)$, while women whose fathers had a history of T2DM showed only a slight tendency to develop T2DM, but it was statistically non-significant in the univariate analysis $(p=0.073)$ ( - Table 2).

Pre-gestational weight was higher in women who developed T2DM compared with the ones who maintained NGT (77.4 \pm 16.7 versus $69.0 \pm 13.5 ; p=0.031$ ), and pre-pregnancy BMI was also higher ( $30.6 \pm 6.0$ versus $27.4 \pm 5.5$; $p=0.028)($ - Table 2).

Women who progressed to T2DM in the postpartum period had the diagnosis of GDM at $28.3 \pm 5.7$ weeks of pregnancy, whereas the NGT women at $31.1 \pm 4.3$ weeks, showing an early diagnosis of GDM for patients with later T2DM $(p=0.019)$. Comparing the fasting plasma glucose of the first trimester of pregnancy among the four groups, those who progressed to T2DM had higher glucose values $(p<0.001)$. Plasma glucose obtained by the OGTT during pregnancy showed difference between the groups, with higher mean levels of fasting plasma glucose and 2-hour plasma glucose in women who progressed to T2DM. The mean hemoglobin A1c test during pregnancy was also higher in women with T2DM $(p<0.001)$ (-Table 2 ).

Considering the categorical variables, there was only a significant difference regarding insulin need (or need of an additional therapy like metformin) in the gestational period, being more frequent for the patients who developed T2DM in the postpartum period $(p<0.001)$. It is important to stress that only two patients used metformin during pregnancy, and that women with postpartum T2DM $(p=0.016)$ were the ones who needed higher doses of insulin during pregnancy (-Table 2).

The time elapsed from the first appointment in the GDM care clinic to the postpartum OGTT was longer for patients with T2DM $(p<0.001)$ (-Table 2).

A multivariate analysis of binary logistic regression was used to evaluate the independent risk factors for the development of T2DM, IFG and IGT. Regarding T2DM, the following parameters were significant: a father with T2DM (OR $=5.67 ; 95 \% \mathrm{CI}=1.64-19.59 ; p=0.006$ ); fasting plasma glucose value in the first trimester of pregnancy $(\mathrm{OR}=1.07$;
$95 \% \mathrm{CI}=1.03-1.11 ; p=0.001) ;$ and insulin use during pregnancy $(\mathrm{OR}=15.92 ; 95 \% \mathrm{CI}=5.54-45.71 ; p<0.001)$ (-Table 3).

Concerning the IFG, a mother with T2DM (OR $=3.15 ; 95 \%$ $\mathrm{CI}=1.43-6.97 ; p=0.005)$ and fasting plasma glucose in the first trimester of pregnancy $(\mathrm{OR}=1.04 ; 95 \% \mathrm{CI}=1.01-1.08$; $p=0.008$ ) were relevant risk factors. On the progression to IGT, fasting plasma glucose in the first trimester of pregnancy $(\mathrm{OR}=1.04 ; 95 \% \mathrm{CI}=1.00-1.07 ; p=0.022)$ and insulin need during pregnancy $(\mathrm{OR}=2.29 ; 95 \% \mathrm{CI}=1.13-4.64$; $p=0.021$ ) were significant factors ( - Table 3 ).

\section{Discussion}

We observed a high incidence of abnormal glucose tolerance after delivery in women with history of GDM, as shown in other studies. ${ }^{15,16}$ In our population of 279 patients, $12.2 \%$ were diagnosed with T2DM; $20.8 \%$ with isolated IFG; and $12.5 \%$ with IGT. The systematic review of Bellamy et $\mathrm{al}^{8}$ showed that women with previous GDM had a 7-fold higher chance of developing T2DM in the future. In a Brazilian cohort, a reevaluation performed 4 to 8 years after pregnancy showed a 1.9-fold increased risk of developing any abnormal glucose tolerance in patients with history of GDM. ${ }^{15}$

Our study showed that women with a family history of T2DM, higher pre-pregnancy BMI, earlier diagnosis of GDM, higher levels of plasma glucose at the diagnosis of GDM, and the need of insulin are the ones with an increased risk of developing T2DM in the postpartum period.

Regarding the age at GDM diagnosis and the progression to T2DM, many studies have not shown a link between those variables. ${ }^{9,14,17-21}$ Additionally, we have not found an age difference between women who progressed to T2DM, IFG, or IGT compared with the ones who maintained the NGT.

Early gestational age at the diagnosis of GDM was associated with the progression to T2DM, a finding also described by Bartha et al, ${ }^{22}$ who reported the early diagnosis of GDM in the first half of pregnancy as a risk factor for the onset of T2DM. Other studies have also shown this association, ${ }^{18,19,23}$ while some do not corroborate such finding. ${ }^{17,20}$ 


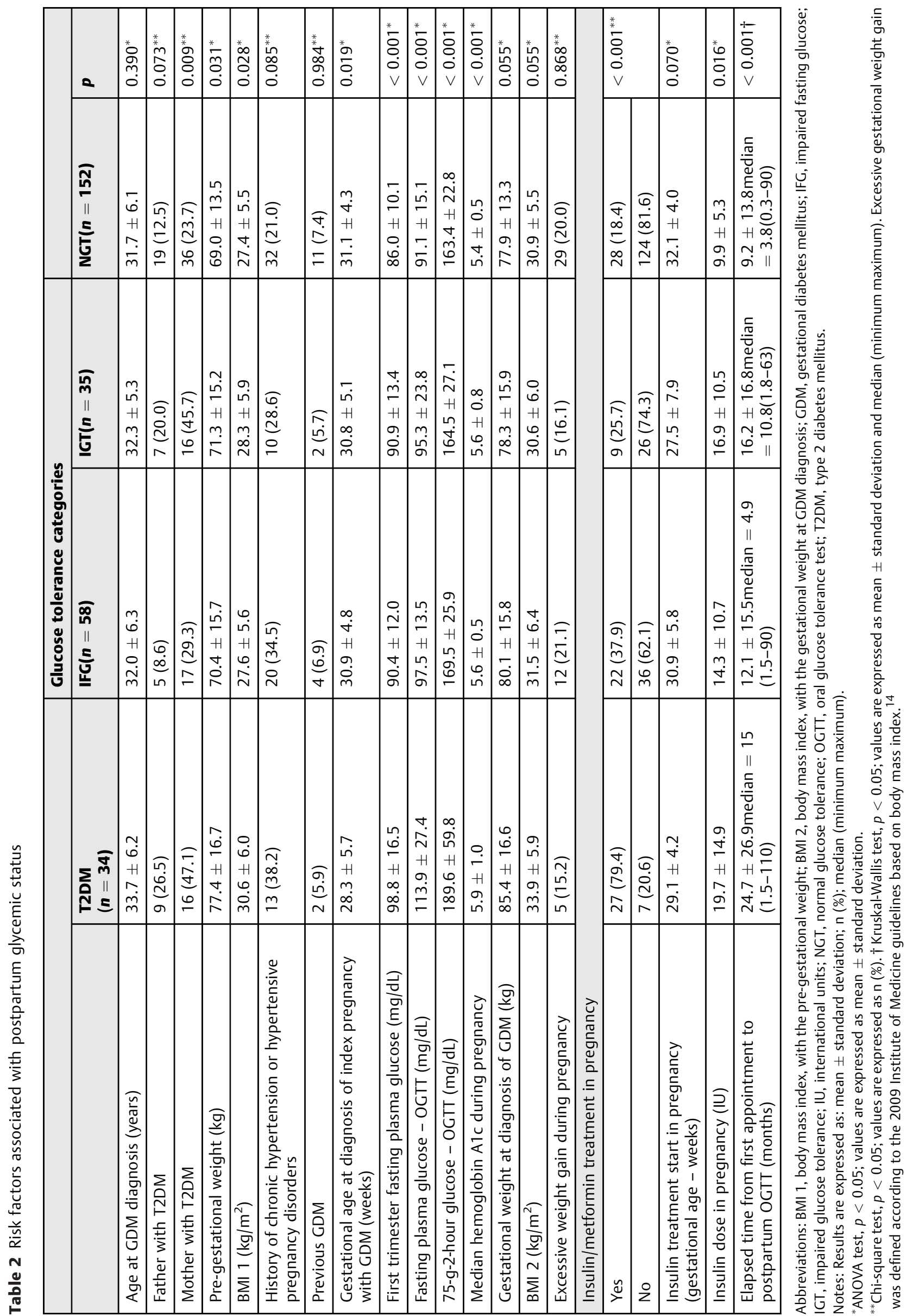


Table 3 Risk factors for postpartum T2DM, IGT, and IFG - multivariate analysis

\begin{tabular}{|c|c|c|}
\hline Risk factors for T2DM & $p$ & OR [95\%Cl] \\
\hline First trimester fasting plasma glucose $(\mathrm{mg} / \mathrm{dL})$ & 0.001 & $1.07[1.03-1.11]$ \\
\hline Father with T2DM & 0.006 & 5.67 [1.64-19.59] \\
\hline Insulin/metformin treatment in pregnancy & $<0.001$ & $15.92[5.54-45.71]$ \\
\hline \multicolumn{3}{|l|}{ Risk factors for IGT } \\
\hline First-trimester fasting plasma glucose (mg/dL) & 0.008 & $1.04[1.01-1.08]$ \\
\hline Mother with T2DM & 0.005 & $3.15[1.43-6.97]$ \\
\hline \multicolumn{3}{|l|}{ Risk factors for IFG } \\
\hline First trimester fasting plasma glucose (mg/dL) & 0.022 & $1.04[1.00-1.07]$ \\
\hline Insulin/metformin treatment in pregnancy & 0.021 & $2.29[1.13-4.64]$ \\
\hline
\end{tabular}

Abbreviations: 95\% Cl, 95\% confidence interval; IFG, impaired fasting glucose; IGT, impaired glucose tolerance; OR, odds ratio; T2DM, type 2 diabetes mellitus.

Note: $p<0.05$.

Considering family history of T2DM and the risk of developing T2DM among women with GDM, some authors have not found the link we observed in our study. ${ }^{18-20,24}$ We demonstrated that women who had GDM and whose mothers were diabetic presented higher rates of T2DM postpartum, in the univariate analysis, whereas the paternal history of T2DM showed a 5.67-fold increase risk of future T2DM. Had our sample of patients been larger, we could have possibly found the mother history with T2DM as an independent factor of progression to T2DM, as shown with IGT (OR $=3.15 ; 95 \% \mathrm{CI}=1.43-6.97 ; p=0.005)$. Several authors have also confirmed the association between positive family history of T2DM and risk of developing T2DM during the postpartum period. ${ }^{25,26}$ The Brazilian cohort of Weinert et $\mathrm{al}^{26}$ found that family history of T2DM was one of the factors associated with the prevalence of hyperglycemia in the postpartum period.

Several studies have associated the pre-pregnancy BMI of women with GDM with the risk of T2DM, ${ }^{9,17,18,24,27}$ but others have not corroborated that connection. ${ }^{28}$ Kwak et al ${ }^{29}$ showed that obesity was a risk factor for the progression to T2DM. Another study has related central obesity at the moment of GDM diagnosis to an increased risk for glucose metabolism alterations in the postpartum period. ${ }^{15}$ In our analysis, weight and pre-pregnancy BMI were associated with the development of T2DM. We have not identified a connection between weight gain in pregnancy and T2DM, which has also been described in other studies. ${ }^{24,30}$

Kim et $\mathrm{al}^{9}$ pointed out the association between the high level of fasting plasma glucose during pregnancy in women with GDM and the progression to T2DM. Our study verified similar results, since the patients who had higher fasting plasma glucose in the beginning of pregnancy showed an increased rate of postpartum abnormal glucose tolerance, standing out as a risk factor, apart from the progression of all of the evaluated glycemic outcomes, which could reflect decreased pancreatic reserve before pregnancy or aspects such as the aggravation or setup of obesity during pregnancy. Other studies also linked high levels of fasting plasma glucose in OGTT during pregnancy to a greater frequency of T2DM development in the postpartum period. ${ }^{17,23,24,27}$ Chew et $\mathrm{al}^{27}$ observed that the elevated fasting plasma glucose during pregnancy was an independent risk factor for T2DM, for isolated IFG, and for the association of IFG and IGT $(p<0.05)$. Schaefer-Graf et $\mathrm{al}^{23}$ reported a risk of developing T2DM 21-fold higher if the fasting plasma glucose during pregnancy was higher than $121 \mathrm{mg} / \mathrm{dL}$. Therefore, fasting plasma glucose seems to be the most important variable for the establishment of T2DM in the postpartum period, ${ }^{23,31}$ and remains an independent predictor for T2DM in long-term analyses. ${ }^{24}$ However, an Australian study with 5,470 women with GDM did not confirm the association between fasting plasma glucose and the risk of T2DM. ${ }^{32}$ The study verified the rate with glycemic levels 1 hour after glucose in OGTT, but fasting plasma glucose and 2-hour after glucose overload in the OGTT were not associated with the development of T2DM during follow-up, which lasted 2.5 years for $43.8 \%$ of the women, and 15 years for $5.1 \%$.

We observed the association between the mean hemoglobin A1c during pregnancy and the postpartum T2DM diagnosis $(p<0.001)$. Ekelund et $\mathrm{al}^{25}$ have shown a 4.8fold increased risk of T2DM in a 5-year follow-up if hemoglobin A1c was $\geq 5.7 \%$ (National Glycohemoglobin Standardization Program) or the equivalent hemoglobin A1c was $\geq 4.7 \%$ with the Swedish Mono S method, but the association with fasting plasma glucose levels has been more significant.

We related the insulin need during pregnancy to the progression of abnormal glucose tolerance. Among the patients diagnosed with T2DM in the postpartum period, 79.4\% used insulin, while among the ones who maintained NGT, only $18.4 \%$ needed insulin treatment. In a multivariate analysis, insulin need was associated with a 15.92-fold increased risk of progressing to T2DM. Insulin treatment during pregnancy has been consistently associated with the development of long-term T2DM, but this finding could simply reflect the degree of fasting hyperglycemia. Some studies have corroborated the connection between the need 
for insulin and the risk of T2DM, ${ }^{19,20,26,32}$ while others have not. $^{21,24}$ It should be considered that insulin use during pregnancy for the treatment of GDM depends on local protocols and on the patient's acceptance; therefore, it is not surprising that such an association is inconsistent in different studied populations.

According to the literature, the frequency of T2DM in women with previous GDM varies between 2.6 and 70\%. ${ }^{6,9,21}$ Feig et $\mathrm{al}^{30}$ estimated the probability of developing T2DM after GDM in 3.7\% over 9 months after delivery, and 18.9\% 9 years later. This variation is due to the great diversity of tests, selection bias, and elapsed time in the follow-up especially. In our study, we found an incidence of $12.2 \%$ of T2DM, observing an important variation concerning time of follow-up, with a mean of $24.7 \pm 26.9$ months between labor and the disease diagnosis.

Patients with GDM in our study are systematically guided and encouraged to return in 6 to 12 weeks after labor and subsequently every 6 months or annually, depending on the results. Nevertheless, the majority did not return for reevaluation, and only $18.4 \%$ of them had some postpartum OGTT, which was a limiting factor in our study. The lack of follow-up is also reported by several other authors, with rates of reevaluation fluctuating between 20 and 50.2\%. ${ }^{33-38}$ The meta-analysis of Tovar et $\mathrm{al}^{39}$ checked that the time elapsed between labor and the reevaluation of the women who had been diagnosed with GDM was greater than recommended in most of the analyzed studies. One of the exceptions is Australia, where there is great focus on tracking T2DM in the postpartum period, with data showing levels of up to $73 \%$ of follow-up. ${ }^{40}$ However, when comparing patients who did not return after labor to the ones who returned for reevaluation, we did not observe significant differences in basal characteristics, family history of T2DM, or use of insulin/metformin during pregnancy. The only difference was related to the gestational age at GDM diagnosis, which was earlier in the included patients, a fact that had no correlation with the progression of those patients during pregnancy according to the evaluated parameters.

The lack of follow-up was possibly due to the difficulty in collecting patients after labor, probably because the first laboratorial reevaluation, when the bond between the patient and the study was established, matched the period of adaptation of the woman to the newborn and its multiple demands. Another hypothesis, which could have the same reason, is that the reevaluation of the glucose tolerance status was performed in health care centers closer to the patient's home.

Another limitation in our study was related to the criteria used for the diagnosis of GDM, which varied over the followup time. It is important to note that there is still no consensus regarding the ideal criteria for the diagnosis. We followed, until 2011, the criteria then current in our country, those of the $2^{\text {nd }}$ Meeting of the Diabetes and Pregnancy Task Force, and thereafter we started to use the recommendations of ADA, ${ }^{10}$ now the most accepted criteria. That division may have set a limitation to the study. Previously, the criteria recommended by the World Health Organization (WHO) had been followed for the diagnosis of GDM, the same cutoff used when not pregnant (fasting plasma glucose $\geq 126 \mathrm{mg} / \mathrm{dL}$ or plasma glucose 2-hour after overload with 75-g glucose $\geq 140 \mathrm{mg} / \mathrm{dL}) .{ }^{41}$ However, in our study we chose to use the criteria of the $2^{\text {nd }}$ Meeting of the Diabetes and Pregnancy Task Force, which included an intermediary category between normal and diabetes, the impaired fasting glucose (glucose between 110 and $126 \mathrm{mg} / \mathrm{dL}$ ) to diagnose GDM. This could have been considered a possible bias of the sample used in our study, that is, a greater number of patients being diagnosed with the disease at that time. However, we do not consider that as a limitation affecting our results, since currently the cutoff point of fasting plasma glucose is even lower, and the criteria for the GDM diagnosis have changed considerably over time and are still quite controversial among numerous institutions and experts who study diabetes and pregnancy.

Lastly, we showed that some characteristics present during pregnancy may help identify women most likely to develop abnormal glucose tolerance in the postpartum period. Those characteristics could be used to assist the adoption of prevention strategies based on individual risk in our population, focusing on patients with a higher risk, in a situation of limited financial resources. Several studies have shown that individuals with a high risk for the development of T2DM (IFG, IGT, patients with history of GDM) could significantly decrease the emergence rate of T2DM through some specific interventions. ${ }^{11,12,42}$ Those measures include programs of intensive lifestyle changes, such as diet and regular physical activity, and the use of medications such as metformin, $\alpha$-glucosidase inhibitors, orlistat, and thiazolidinedione, all of which have been shown to decrease the incidence of T2DM. Regarding the use of medication in patients with a history of GDM, the use of metformin was shown to decrease the risk of T2DM in $\sim 50 \%$ of patients in the study of Ratner et al, ${ }^{11}$ from the Diabetes Prevention Program (DPP). Aroda et $\mathrm{al}^{12}$ recently published a 10 -year follow-up study of DPP women. Among the women with a history of GDM, the group that had changed their lifestyle intensively showed a decrease in incidence of T2DM in 35\%, and the group using metformin had a $40 \%$ reduction, while those in the placebo group showed a $48 \%$ higher risk of developing the disease. ${ }^{12}$ Regarding the randomized women in this study with no previous history of GDM, those who participated in the lifestyle changes lowered the risk for T2DM, while those randomized for the use of metformin did not show a decline in the incidence of T2DM. These data suggest that metformin may be more effective in women with previous GDM than in women without this history, suggesting that it might be an interesting medication for use in this population.

Strategies to increase the return index for the glucose status reevaluation in the postpartum, and eventually to prevent T2DM, should include the following: guidance during prenatal care and immediately at postpartum, showing the importance of the reevaluation, and even contact with the patients (through phone calls, for example) if they do not attend the appointment. 
Health policy must be encouraged to make these women aware and to assure their return after labor for adequate reevaluation. Some characteristics present during pregnancy may help identify the women most likely to develop abnormal glucose tolerance in the future and, therefore, assist in the adoption of prevention strategies based on the individual risk.

\section{References}

1 National Diabetes Data Group. Classification and diagnosis of diabetes mellitus and other categories of glucose intolerance. Diabetes 1979;28(12):1039-1057

2 Metzger BE, Lowe LP, Dyer AR, et al; HAPO Study Cooperative Research Group. Hyperglycemia and adverse pregnancy outcomes. N Engl J Med 2008;358(19):1991-2002

3 Metzger BE, Gabbe SG, Persson B, et al; International Association of Diabetes and Pregnancy Study Groups Consensus Panel. International association of diabetes and pregnancy study groups recommendations on the diagnosis and classification of hyperglycemia in pregnancy. Diabetes Care 2010;33(3):676-682

4 American Diabetes Association. Diagnosis and classification of diabetes mellitus. Diabetes Care 2013;36(Suppl 1):S67-S74

5 Sacks DA, Hadden DR, Maresh M, et al; HAPO Study Cooperative Research Group. Frequency of gestational diabetes mellitus at collaborating centers based on IADPSG consensus panel-recommended criteria: the Hyperglycemia and Adverse Pregnancy Outcome (HAPO) Study. Diabetes Care 2012;35(3):526-528

6 Guariguata L, Linnenkamp U, Beagley J, Whiting DR, Cho NH. Global estimates of the prevalence of hyperglycaemia in pregnancy. Diabetes Res Clin Pract 2014;103(2):176-185

7 Trujillo J, Vigo A, Duncan BB, et al. Impact of the International Association of Diabetes and Pregnancy Study Groups criteria for gestational diabetes. Diabetes Res Clin Pract 2015;108(2):288-295

8 Bellamy L, Casas JP, Hingorani AD, Williams D. Type 2 diabetes mellitus after gestational diabetes: a systematic review and metaanalysis. Lancet 2009;373(9677):1773-1779

9 Kim C, Newton KM, Knopp RH. Gestational diabetes and the incidence of type 2 diabetes: a systematic review. Diabetes Care 2002;25(10):1862-1868

10 American Diabetes Association. Standards of medical care in diabetes-2011. Diabetes Care 2011;34(Suppl 1):S11-S61

11 Ratner RE, Christophi CA, Metzger BE, et al; Diabetes Prevention Program Research Group. Prevention of diabetes in women with a history of gestational diabetes: effects of metformin and lifestyle interventions. J Clin Endocrinol Metab 2008;93(12):4774-4779

12 Aroda VR, Christophi CA, Edelstein SL, et al; Diabetes Prevention Program Research Group. The effect of lifestyle intervention and metformin on preventing or delaying diabetes among women with and without gestational diabetes: the Diabetes Prevention Program outcomes study 10-year follow-up. J Clin Endocrinol Metab 2015;100(4):1646-1653

13 Reichelt AJ, Oppermann MLR, Schmidt MI. Recomendações da 2.. reunião de grupo de trabalho em diabetes e gravidez. Arq Bras Endocrinol Metabol 2002;46(5):574-581

14 Institute of Medicine. National Research Council. Committee to Reexamine IOM Pregnancy Weight Guidelines. Weight gain during pregnancy: reexamining the guidelines. Washington (DC): The National Academies Press; 2009

15 Jacob Reichelt AA, Ferraz TM, Rocha Oppermann ML, et al. Detecting glucose intolerance after gestational diabetes: inadequacy of fasting glucose alone and risk associated with gestational diabetes and second trimester waist-hip ratio. Diabetologia 2002;45(3): 455-457
16 Silva MRG, Calderon IdeM, Gonçalves LC, Aragon FF, Padovani CR, Pimenta WdeP. Occurrence of diabetes mellitus in women with prior gestational hyperglycemia. Rev Saude Publica 2003;37(3): 345-350

17 Sivaraman SC, Vinnamala S, Jenkins D. Gestational diabetes and future risk of diabetes. J Clin Med Res 2013;5(2):92-96

18 Kjos SL, Peters RK, Xiang A, Henry OA, Montoro M, Buchanan TA. Predicting future diabetes in Latino women with gestational diabetes. Utility of early postpartum glucose tolerance testing. Diabetes 1995;44(5):586-591

19 Catalano PM, Vargo KM, Bernstein IM, Amini SB. Incidence and risk factors associated with abnormal postpartum glucose tolerance in women with gestational diabetes. Am J Obstet Gynecol 1991;165(4 Pt 1):914-919

20 Lam KS, Li DF, Lauder IJ, Lee CP, Kung AW, Ma JT. Prediction of persistent carbohydrate intolerance in patients with gestational diabetes. Diabetes Res Clin Pract 1991;12(3):181-186

21 Steinhart JR, Sugarman JR, Connell FA. Gestational diabetes is a herald of NIDDM in Navajo women. High rate of abnormal glucose tolerance after GDM. Diabetes Care 1997;20(6):943-947

22 Bartha JL, Martinez-del-Fresno P, Comino-Delgado R. Postpartum metabolism and autoantibody markers in women with gestational diabetes mellitus diagnosed in early pregnancy. Am J Obstet Gynecol 2001;184(5):965-970

23 Schaefer-Graf UM, Buchanan TA, Xiang AH, Peters RK, Kjos SL. Clinical predictors for a high risk for the development of diabetes mellitus in the early puerperium in women with recent gestational diabetes mellitus. Am J Obstet Gynecol 2002;186(4): 751-756

24 Coustan DR, Carpenter MW, O'Sullivan PS, Carr SR. Gestational diabetes: predictors of subsequent disordered glucose metabolism. Am J Obstet Gynecol 1993;168(4):1139-1144, discussion 1144-1145

25 Ekelund M, Shaat N, Almgren P, Groop L, Berntorp K. Prediction of postpartum diabetes in women with gestational diabetes mellitus. Diabetologia 2010;53(3):452-457

26 Weinert LS, Mastella LS, Oppermann ML, Silveiro SP, Guimarães LS, Reichelt AJ. Postpartum glucose tolerance status 6 to 12 weeks after gestational diabetes mellitus: a Brazilian cohort. Arq Bras Endocrinol Metabol 2014;58(2):197-204

27 Chew WF, Rokiah P, Chan SP, Chee WS, Lee LF, Chan YM. Prevalence of glucose intolerance, and associated antenatal and historical risk factors among Malaysian women with a history of gestational diabetes mellitus. Singapore Med J 2012;53(12):814-820

28 Buchanan TA, Xiang AH, Kjos SL, Trigo E, Lee WP, Peters RK. Antepartum predictors of the development of type 2 diabetes in Latino women 11-26 months after pregnancies complicated by gestational diabetes. Diabetes 1999;48(12):2430-2436

29 Kwak SH, Choi SH, Jung HS, et al. Clinical and genetic risk factors for type 2 diabetes at early or late post partum after gestational diabetes mellitus. J Clin Endocrinol Metab 2013;98(4):E744-E752

30 Feig DS, Zinman B, Wang X, Hux JE. Risk of development of diabetes mellitus after diagnosis of gestational diabetes. CMAJ 2008;179(3):229-234

31 Aberg AE, Jönsson EK, Eskilsson I, Landin-Olsson M, Frid AH. Predictive factors of developing diabetes mellitus in women with gestational diabetes. Acta Obstet Gynecol Scand 2002;81(1): $11-16$

32 Lee AJ, Hiscock RJ, Wein P, Walker SP, Permezel M. Gestational diabetes mellitus: clinical predictors and long-term risk of developing type 2 diabetes: a retrospective cohort study using survival analysis. Diabetes Care 2007;30(4):878-883

33 Stasenko M, Cheng YW, McLean T, Jelin AC, Rand L, Caughey AB. Postpartum follow-up for women with gestational diabetes mellitus. Am J Perinatol 2010;27(9):737-742

34 Lawrence JM, Black MH, Hsu JW, Chen W, Sacks DA. Prevalence and timing of postpartum glucose testing and sustained glucose 
dysregulation after gestational diabetes mellitus. Diabetes Care 2010;33(3):569-576

35 Ferrara A, Peng T, Kim C. Trends in postpartum diabetes screening and subsequent diabetes and impaired fasting glucose among women with histories of gestational diabetes mellitus: A report from the Translating Research Into Action for Diabetes (TRIAD) Study. Diabetes Care 2009;32(2): 269-274

36 Ogonowski J, Miazgowski T. The prevalence of 6 weeks postpartum abnormal glucose tolerance in Caucasian women with gestational diabetes. Diabetes Res Clin Pract 2009;84(3): 239-244

37 Almario CV, Ecker T, Moroz LA, Bucovetsky L, Berghella V, Baxter JK. Obstetricians seldom provide postpartum diabetes screening for women with gestational diabetes. Am J Obstet Gynecol 2008; 198(5):528.e1-528.e5
38 McGovern A, Butler L, Jones S, et al. Diabetes screening after gestational diabetes in England: a quantitative retrospective cohort study. Br J Gen Pract 2014;64(618):e17-e23

39 Tovar A, Chasan-Taber L, Eggleston E, Oken E. Postpartum screening for diabetes among women with a history of gestational diabetes mellitus. Prev Chronic Dis 2011;8(6):A124

40 Morrison MK, Collins CE, Lowe JM. Postnatal testing for diabetes in Australian women following gestational diabetes mellitus. Aust N Z J Obstet Gynaecol 2009;49(5):494-498

41 World Health Organization. Definition, diagnosis and classification of diabetes mellitus and its complications: report of a WHO consultation. Geneva: WHO; 1999

42 Buchanan TA, Xiang AH, Peters RK, et al. Preservation of pancreatic $\beta$-cell function and prevention of type 2 diabetes by pharmacological treatment of insulin resistance in high-risk hispanic women. Diabetes 2002;51(9):2796-2803 